\title{
Percutaneous Retrograde Cardioplegia in Minimal Access Aortic Valve Replacement Reduces Aortic Cross-Clamping Time Significantly
}

\author{
Thierry V. Scohy ${ }^{1^{*}}$, Gijs van Kerckhoven ${ }^{1}$, Mohamed Bentala ${ }^{2}$, Sander Bramer ${ }^{2}$, \\ Joost AM. Labout ${ }^{1}$, Bastiaan M. Gerritse ${ }^{1}$ \\ ${ }^{I}$ Department of Anaesthesiology and Intensive Care, Amphia Hospital, Breda, The Netherlands \\ ${ }^{2}$ Department of Cardiothoracic Surgery, Amphia Hospital Breda, The Netherlands
}

*Corresponding Author: Thierry V. Scohy, Department of Anaesthesiology and Intensive Care, Amphia Hospital, Breda, The Netherlands, Email: tscohy@amphia.nl

\begin{abstract}
:
Introduction: One of the main obstacles of minimally invasive surgery for aortic valve replacement (M-AVR) is the increased cardiopulmonary bypass $(C P B)$ and aortic cross-clamping time. We hypothesize that the use of a percutaneous coronary sinus catheter to deliver retrograde cardioplegia may facilitate surgery and reduce CPB- and aortic cross-clamping time.
\end{abstract}

Methods: Data were collected prospectively at the Amphia Hospital, Breda, the Netherlands from May 2014 to May 2016 and were analysed retrospectively. A total of 40 M-AVR patients were included. In all cases warm blood cardioplegia was used. The initial dose of cardioplegia was administered antegradely through the aortic root in all 40 patients. In all patients cardioplegia was repeated each 20 minutes. Patients with a percutaneous coronary sinus catheter received their following doses of cardioplegia retrogradely, whereas patients without a coronary sinus catheter received cardioplegia selectively through the coronary ostia.

Results: 23 patients received retrograde cardioplegia through a percutaneous coronary sinus catheter versus 17 patients that received their cardioplegia solely antegradely. Mean aortic cross-clamp time was

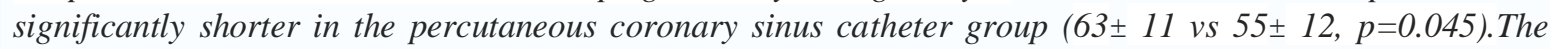
mean $C P B$ time was 8 minutes shorter in the percutaneous coronary sinus catheter group, although this was not significant (82 $\min \pm 14$ vs $74 \mathrm{~min} \pm 14, p=0.075$ ). Maximum Troponin $T$ did not differ significantly between the two groups (0.12 [0.08] vs 0.13 [0.11], $p=0.227)$.

Conclusion: Percutaneous retrograde cardioplegia administered through a coronary sinus catheter in minimal invasive AVR reduces aortic cross-clamping time significantly.

Keywords: retrograde cardioplegia, minimally invasive surgery aortic valve replacement, percutaneous coronary sinus catheter

\section{INTRODUCTION}

Minimally invasive surgery for aortic valve replacement (M-AVR) was introduced in 1996 and is now an acknowledged and established method of surgery. Compared to conventional sternotomy for aortic valve replacement (AVR), M-AVR diminishes postoperative ventilation time, reduces pain, hospital length of stay, time until return to full activity, and decreases use of blood products [1-10].Although M-AVR has a mortality rate comparable to conventional AVR [1-8], one of the main obstacles of M-AVR is the increased cardiopulmonary bypass (CPB) and aortic cross-clamping time $[9,10]$.

At the Amphia Hospital Breda, The Netherlands, intermittent 20:1 diluted warm blood cardioplegia solution, administered at a 20-minutes interval, is used since many years. Unfortunately repeated [antegrade] warm blood cardioplegia delivery selectively through both coronary ostia can be time consuming.

Labriola et al. published in 2016 that the use of necklines may facilitate surgery by reducing the number of lines to be inserted and removed by 
surgeons, and provide an unobstructed view of the surgical field [11].Labriola et al. also showed that retrograde cardioplegia can be delivered through a percutaneous coronary sinus catheter (CSC), guided by trans oesophageal echography (TEE), via the right internal jugular vein (PR9 Catheter, Edwards Scientific, Salt Lake City, Utah USA), positioned in the coronary sinus [11]. To show possible benefits of this retrograde cannula we analysed our $\mathrm{M}$ AVR data retrospectively, focussing on CPB time and aortic cross-clamping time.

\section{MATERIALS \&METHODS}

\subsection{Study design, setting and patients}

Data were prospectively collected at the Amphia Hospital, Breda, the Netherlands from May 2014 to May 2016 and analysed retrospectively. A total of 40 M-AVR patients, diagnosed with severe aortic stenosis, were included. Patients were 18 years or older and were operated by either one of two experienced cardiothoracic surgeons in M-AVR (MB and SB). In our institution, warm blood cardioplegia is intermittently delivered, every 20 minutes, with the purpose of inducing and maintaining cardioplegic arrest. The cardioplegic solution is produced by mixing oxygenated blood with a hyperkalemic solution in a 20:1 ratio. The initial dose of cardioplegia was administered antegrade through the aortic root in all 40 patients. In all patients cardioplegia was repeated after 20 minutes. Patients, with a percutaneous coronary sinus catheter, received their following doses of cardioplegia retrogradely. . Patients without a percutaneous coronary sinus catheter received their following doses antegradely by selective cannulation of the coronayostia. Patients received either a bio prosthetic or mechanical valve.

The percutane coronary sinus catheter (retrograde cardioplegia) was solely employed when one of the two cardiothoracic anaesthesiologists, who are experienced in the use of this device, were available (BG and TS).The standard cardiac-anaesthesia protocol was used in all patients. After induction with midazolam, sufentanil and rocuronium, anaesthesia was maintained with sevoflurane and remifentanil. As patients were not subjected to investigational actions the medical ethics commission was notified, but further approval of a medical ethics commission was not necessary. Patient confidentiality was guaranteed according to the Dutch law on personal data protection.

\subsection{Operative technique}

The operative technique of M-AVR has been extensively described [12-15].

A vertical small $5 \mathrm{~cm}$ skin incision is made on the region of the manubrium sterni joint. A partial J-sternotomy is performed with a Hall®Saw. The $\mathbf{J}$ part of the bone incision is performed with the unprotected blade of the Hall@Saw, from lateral to medial and from the second or the third intercostal space, depending on the body habitus of the patient. The pericardium is opened and the pericardium edges are pulled out through the incision, and fixed to the skin. The right femoral vein is used for vein cannulation. A Sorin double staged vein cannula is placed through the femoral vein using the Seldinger technique, positioned under TEE guidance. The arterial cannulation is done centrally in the ascending aorta. An aortic root needle is placed. Venting takes place through the aortic valve. The retrograde cardioplegia coronary sinus catheter is placed percutaneous through the right internal jugular vein guided by TEE guidance. All intended percutaneous coronary sinus catheters are adequately positioned without any negative side effects. The aorta is cross-clamped using a Cosgrove flexible aortic cross-clamp. Cardioplegia delivery was considered successful when dark blood appeared from both coronary ostia administration.

\subsection{Data collection}

Data were retrospectively collected; baseline characteristics, such as patient age and sex, preoperative $\mathrm{Hb}$, and creatinine. Pre-operative comorbidities, such as left ventricular dysfunction, aortic valve regurgitation and left ventricular hypertrophy. Collected operative characteristics were CPB time and aortic crossclamping time. Postoperative outcome measures were maximum Troponin $\mathrm{T}$, postoperative myocardial infarction, postoperative potassium, maximum creatinine and postoperative adverse events.

Primary we compared CPB time and aortic cross clamping time between the PR9 retrograde- and the anterograde cardioplegia group. Secondly, we investigated whether the difference in clamping time led to difference in myocardial damage, measured by maximum Troponin $\mathrm{T}$ and 
Percutaneous Retrograde Cardioplegia in Minimal Access Aortic Valve Replacement Reduces Aortic Cross-Clamping Time Significantly

the occurrence of myocardial infarction postoperatively.

\subsection{Definition of adverse events}

Death in relation to surgery was defined as any death occurring during the same hospital admission as for the surgery. Renal disorders were defined as an elevated creatinine, decreased urine output and the necessity for continuous veno-venous hemofiltration $(\mathrm{CVVH})$. Postoperative myocardial infarction was defined as a changing ECG with signs of ischemia and elevated troponin $\mathrm{T}$. The category other adverse events was used as a collection category.

\subsection{Statistics}

All data were analysed using SPSS Statistics Version 22 (IBM, Armonk, NY, USA).

Categorical variables are described as numbers (percentages). Continuous variables were described as mean ( \pm standard deviation) if normally distributed, or median [interquartile range] if not normally distributed. Statistical analysis between the two groups was made using the unpaired $\mathrm{T}$ test for numerical variables and the Pearson Chi Square for categorical data. Statistical significance was accepted as $p<0.05$.

\section{Results}

A total of 40 patients had elective M-AVR during the study period. Twenty-three patients received retrograde cardioplegia through a percutaneous coronary sinus catheter (Retrograde M-AVR group). The patients demographic characteristics are listed in Table 1.Operative characteristics are presented in Table 2. Mean aortic cross-clamping time was significantly shorter in the retrograde M-AVR group (63 $\min \pm 11$ vs $55 \min \pm 12, \mathrm{p}=0.045$ ). The mean CPB time was slightly longer in the solely antegrade cardioplegia M-AVR group, but did not differ significantly ( $82 \min \pm 14$ vs $74 \min \pm 14, \mathrm{p}=0.075$ ).

Table1. Baseline characteristics

\begin{tabular}{|l|l|l|l|}
\hline & $\begin{array}{l}\text { Percutaneous } \\
\text { M-AVR }\end{array}$ & $\begin{array}{l}\text { Antegrade } \\
\text { M-AVR }\end{array}$ & P-value \\
\hline TOTAL & N=23 & N=17 & \\
\hline Sex (Male) & $15(65.2)$ & $11(64.7)$ & 0.973 \\
\hline Age & $69.00 \pm 11$ & $66.39 \pm 12$ & 0.200 \\
\hline BMI & $27.1 \pm 4.8$ & $26.2 \pm 4.6$ & 0.347 \\
\hline NYHA Classification & & & 0.726 \\
None & $12(52.2)$ & $10(58.8)$ & \\
I & $1(4.3)$ & $1(5.9)$ & \\
II & $6(26.1)$ & $2(11.8)$ & \\
III & $4(17.4)$ & $4(23.5)$ & 0.621 \\
\hline Euro SCORE I & $5[3-7]$ & $4[0-8]$ & 0.634 \\
\hline Pre-operative Hb (mmol/L) & $8.6 \pm 1.5$ & $8.2 \pm 1.6$ & 0.242 \\
\hline Pre-operative creatinine (umol/L) & $85 \pm 18$ & $80 \pm 23$ & \\
\hline Co-morbidity & & & 0.455 \\
\hline Left ventricular function & & & \\
\hline$<30 \%$ & - & - & $1(5.9)$ \\
\hline $30-50 \%$ & $3(13)$ & $16(94.1)$ & \\
\hline 50\% & $20(87)$ & $3(17.6)$ & 0.166 \\
\hline COPD & $1(4.3)$ & $3(17.6)$ & 0.036 \\
\hline Peripheral arterial disease & - & - & 0.384 \\
\hline CVA & $1(4.3)$ & $3(17.6)$ & 0.036 \\
\hline TIA & - & $3(17.6)$ & 0.397 \\
\hline Diabetes Mellitus type II & $2(8.7)$ & $5(29.4)$ & 0.364 \\
\hline Hypertension & $10(43.5)$ & $4(23.5)$ & 0.298 \\
\hline Hypercholesterolemia & $9(39.1)$ & $1(5.9)$ & 0.239 \\
\hline Pulmonary hypertension & - & - & 0.212 \\
\hline Atrial fibrillation & $2(8.7)$ & $2(11.8)$ & 0.379 \\
\hline Aortic valve regurgitation & $1(4.3)$ & $17(100)$ & 0.122 \\
\hline Left ventricular hypertrophy & $20(87.0)$ & \\
\hline & & & \\
\hline
\end{tabular}


Percutaneous Retrograde Cardioplegia in Minimal Access Aortic Valve Replacement Reduces Aortic Cross-Clamping Time Significantly

BMI: body mass index; NYHA: New York Heart Association classification of dyspnoea; Euro SCORE: additive European System for Cardiac Operative Risk Evaluation; COPD: chronic obstructive pulmonary disease; CVA: cerebrovascular accident; TIA: transient is chemic attack

Qualitative data are given as absolute number (percentage); quantitative data are given as median value \& IQR or mean \&st. dev when normally distributed

Table2. Operative characteristics

\begin{tabular}{|l|l|l|l|}
\hline & $\begin{array}{l}\text { Percutaneous } \\
\text { M-AVR }\end{array}$ & $\begin{array}{l}\text { Ante grade } \\
\text { M-AVR }\end{array}$ & P-value \\
\hline TOTAL & $\mathbf{N = 2 3}$ & $\mathbf{N}=17$ & \\
\hline CPB time $(\mathrm{min})$ & $74.09 \pm 13.54$ & $82.06 \pm 13.709$ & 0.075 \\
\hline ACC time $(\mathrm{min})$ & $54.78 \pm 12.354$ & $62.59 \pm 10.995$ & 0.045 \\
\hline
\end{tabular}

CPB: cardiopulmonary bypass; ACC: aortic cross-clamping

Qualitative data are given as absolute number (percentage); quantitative data are given as median value \& IQR or mean \&st. dev. when normally distributed

The main clinical outcomes of the groups are zero in the retrograde M-AVR group. However, presented in Table 3. Maximum Troponin T did not differ between the two groups $(0.12 \mathrm{umol} / \mathrm{L}$ [0.08] vs $0.13 \mathrm{umol} / \mathrm{L}$ [0.11], $\mathrm{p}=0.227)$. There were two postoperative myocardial infarctions in the ante grade M-AVR group as opposed to this difference was not statistically significant $(\mathrm{p}=0.091)$. One patient in the antegrade M-AVR group required a re-exploration due to excessive drain production, caused by leakage from the aortic seam.

Table3. Postoperative outcomes

\begin{tabular}{|c|c|c|c|}
\hline & $\begin{array}{l}\text { Percutaneous } \\
\text { M-AVR }\end{array}$ & $\begin{array}{l}\text { Ante grade } \\
\text { M-AVR }\end{array}$ & P-value \\
\hline TOTAL & $\mathrm{N}=\mathbf{2 3}$ & $\mathrm{N}=17$ & \\
\hline Maximum Troponin T (umol/L) & $0.12[0.08]$ & $0.13[0.11]$ & 0.227 \\
\hline Postoperative myocardial infarction ${ }^{\#}$ & 0 & $2(11.8)$ & 0.091 \\
\hline Postoperative potassium (mmol/L) & $4.822 \pm 0.4295$ & $4.941 \pm 0.3743$ & 0.365 \\
\hline Maximum creatinine (umol/L) & $87[32]$ & 79 [17] & 0.124 \\
\hline Other adverse events & 0 & $1(5.9)$ & 0.239 \\
\hline \multicolumn{4}{|c|}{$\begin{array}{l}\text { Postoperative MI, defined as: a changing ECG with signs of ischemia and elevated Troponin T (see } \\
\text { Data collection) } \\
\text { Qualitative data are given as absolute number (percentage); quantitative data are given as median } \\
\text { value \& IQR or mean \&st. dev. when normally distributed }\end{array}$} \\
\hline
\end{tabular}

\section{DISCUSSION}

The present study shows that retrograde cardioplegia through a percutaneous coronary sinus catheter does reduce aortic crossclamping time significantly during M-AVR. We also see a tendency of shorter CPB times of mainly 8 minutes in the retrograde cardioplegia M-AVR group. This can be explained by the fact that administering retrograde cardioplegia through a percutaneous coronary sinus catheter, in a setting of M-AVR, facilitates delivery of cardioplegia, as the surgical procedure does not have to be stopped for administration of selective cardioplegia in both coronary ostia, which sometimes can be time-consuming and challenging in M-AVR. Adequate cardioplegia delivery must only be checked, by the appearance of dark fluid from both coronary ostia. As published by Labriola et al. the percutaneous coronary sinus catheter ensure effective retrograde cardioplegia of the heart and allow surgeons to operate in an unobstructed surgical field [11].On the other hand the anaesthesiologist will need some extra time to deploy the percutaneous coronary sinus catheter successfully [11].

Shehada et al. published comparable aortic cross-clamp times (M-AVR $65.6 \pm 18.4$ min vs conventional AVR $64.3 \pm 19.8 \mathrm{~min}, \mathrm{P}=0.25$ ) in his propensity score analysis between M-AVR and conventional AVR ( $\mathrm{n}=585$ in both groups) [10], those aortic cross-clamp times are comparable with our solely antegrade cardioplegia M-AVR (63 $11 \mathrm{~min})$. On the other hand, Shehada et al published much longer operation time compared to a full sternotomy 
because of limited exposure of the heart and much longer CPB times for M-AVR compared with conventional AVR $(93.5 \pm 25$ vs $88 \pm 28$ min, $\mathrm{P}<0.001)[10]$. Our CPB times $(82 \pm 14$ min vs $74 \pm 15 \mathrm{~min}$ ) are much shorter, which can partially be explained by a gain of experience over time.

The main principle of myocardial protection in cardiac surgery is to preserve myocardial function by preventing ischemia with the use of cardioplegia. Therefore, in our institution, warm blood cardioplegia is intermittently delivered in the coronary arteries. We are well aware of the fact that myocardial protection is still a major issue in cardiac surgery, since inadequate protection increases the risk of postoperative cardiac dysfunction. We only saw a significant reduction of aortic cross-clamp time in this study.

The sample size of this pilot study was generally not large enough to detect a significant difference of maximum Troponin $\mathrm{T}(0.12$ $\mathrm{umol} / \mathrm{L}[0.08]$ vs $0.13 \mathrm{umol} / \mathrm{L}$ [0.11], $\mathrm{p}=0.227$ ) between the groups, therefore 948 patients are needed.

Minimal invasive AVR has several advantages such as shorter length of stay $[1,2,3,5,6,8]$ shorter duration of ventilation $[1,2,6,8]$, decreased time until return to full activity [2], improved cosmetics $[4,8,10]$, decreased rate of postoperative renal failure [5] and less postoperative pain [8] compared with conventional AVR. A recent meta-analysis found no significant difference between AVR and MAVR for postoperative atrial fibrillation, myocardial infarctions, pneumonia, pneumothorax, sternal/wound infections or mortality rate [3]. Since our study shows a significant reduced aortic cross-clamp time with the use of a percutaneous coronary sinus catheter for retrograde cardioplegia, additional studies are required to determine whether the use of percutaneous coronary sinus catheter is associated with better outcomes in M-AVR.

\section{CONCLUSION}

Retrograde cardioplegia administered through a percutaneous coronary sinus catheter in minimal invasive AVR reduces aortic cross-clamping time significantly.

\section{REFERENCES}

[1] Tabata M, Umakanthan R, Cohn LH, Bolman RM 3rd, Shekar PS, Chen FY, Couper GS,
Aranki SF. Early and late outcomes of 1000 minimally invasive aortic valve operations. Eur J Cardiothorac Surg. 2008 Apr;33(4):537-41

[2] Brinkman WT, Hoffman W, Dewey TM, Culica D, Prince SL, Herbert MA, Mack MJ, Ryan WH. Aortic valve replacement surgery: comparison of outcomes in matched sternotomy and PORT ACCESS groups. Ann Thorac Surg. $2010 \mathrm{Jul} ; 90(1): 131-5$

[3] Phan K, Xie A, Di Eusanio M, Yan TD. A meta-analysis of minimally invasive versus conventional sternotomy for aortic valve replacement. Ann ThoracSurg 2014;98:1499511

[4] Malaisrie SC, Barnhart GR, Farivar RS, Mehall $\mathrm{J}$, Hummel B, Rodriguez E, Anderson M, Lewis C, Hargrove C, Ailawadi G, Goldman S, Khan J, Moront M, Grossi E, Roselli EE, Agnihotri A, Mack MJ, Smith JM, Thourani VH, Duhay FG, Kocis MT, Ryan WH. Current era minimally invasive aortic valve replacement: techniques and practice. J ThoracCardiovasc Surg. 2014 Jan;147(1):6-14

[5] Bowdish ME, Hui DS, Cleveland JD, Mack WJ, Sinha R, Ranjan R, Cohen RG, Baker CJ, Cunningham MJ, Barr ML, Starnes VA. A comparison of aortic valve replacement via an anterior right minithoracotomy with standard sternotomy: a propensity score analysis of 492 patients. Eur J Cardiothorac Surg. 2016 Feb;49(2):456-6

[6] Gilmanov D, Farneti PA, Ferrarini M, Santarelli F, Murzi M, Miceli A, Solinas M, Glauber M. Fullsternotomy versus right anterior minithoracotomy for isolated aortic valve replacement in octogenarians: a propensity-matched study. Interact CardiovascThorac Surg. 2015 Jun;20(6):732-41

[7] Gilmanov D, Solinas M, Farneti PA, Cerillo AG, Kallushi E, Santarelli F, Glauber M. Minimally invasive aortic valvere placement: 12-years in glecenter experience. Ann Cardiothorac Surg. 2015 Mar;4(2):160-9

[8] Neely RC, Boskovski MT, Gosev I, Kaneko T, McGurk S, Leacche M, Cohn LH. Minimally invasive aortic valve replacement versus aortic valve replacement through full sternotomy: the Brigham and Women's Hospital experience. Ann Cardiothorac Surg. 2015 Jan;4(1):38-48

[9] Brown ML, McKellar SH, Sundt TM, Schaff HV. Ministernotomy versus conventional sternotomy for aortic valve replacement: a systematic review and meta-analysis. J ThoracCardiovasc Surg. 2009; 137(3): 670-679

[10] Shehada S-E, Öztürk Ö, Wottke M, Lange R. Propensity score analysis of outcomes following minimal access versus conventional aortic valve replacement. Eur J CardiothoracSurg 2016;49:464-70. 
[11] Labriola C, Paparella D, Labriola G, Dambruoso P, Cassese M, Speziale G. Reliability of Percutaneous Pulmonary Vent and Coronary Sinus Cardioplegia in the Setting of Minimally Invasive Aortic Valve Replacement: A Single-Center Experience. J CardiothoracVascAnesth.2016 Oct 18. pii: S1053-0770(16)30506-7. doi: 10.1053/j.jvca. 2016.10.016. [Epub ahead of print]

[12] von Segesser LK, Westaby S, Pomar J, Loisance D, Groscurth P, Turina M. Less invasive aortic valve surgery: rationale and technique. Eur J CardiothoracSurg 1999;15(6):781-5

[13] Cohn LH, Adams DH, Couper GS, Bichell DP, Rosborough DM, Sears SP, Aranki SF. Minimally invasive cardiac valve surgery improves patient satisfaction while reducing costs of cardiac valve replacement and repair. Ann Surg 1997;226(4):421-6; discussion 427-8

[14] Doll N, Borger MA, Hain J, Bucerius J, Walther T, Gummert JF, Mohr FW. Minimal access aortic valve replacement: effects on morbidity and resource utilization. Ann ThoracSurg 2002;74(4):S1318-22

[15] Ruttmann E, Gilhofer TS, Ulmer H, Chevtchik O, Kocher A, Schistek R, Laufert G, Mueller LC. Propensity score-matched analysis of aortic valve replacement by mini-thoracotomy. J Heart Valve Dis 2010;19(5):606-14

Citation: Thierry V. Scohy, Gijs van Kerckhoven, Mohamed Bentala, Sander Bramer, Joost AM. Labout, Bastiaan M. Gerritse. Percutaneous Retrograde Cardioplegia in Minimal Access Aortic Valve Replacement Reduces Aortic Cross-Clamping Time Significantly. ARC Journal of Anesthesiology. 2017;2(4):18-23. doi: dx.doi.org/10.20431/2455-9792.0204003.

Copyright: (C) 2017 Authors. This is an open-access article distributed under the terms of the Creative Commons Attribution License, which permits unrestricted use, distribution, and reproduction in any medium, provided the original author and source are credited. 